\title{
DETERMINING THE FRAMEWORK FOR ŽIŽKA MONUMENT 3D REPRODUCTION
}

\author{
Tanja Nuša Kočevar ${ }^{1}$ (D), Anja Škerjanc ${ }^{1}$, Ana Porok ${ }^{2}$, \\ Tomaž Jurca ${ }^{2}$, Matej Pivar ${ }^{1}$, Helena Gabrijelčič Tomc ${ }^{1}$ (iD \\ ${ }^{1}$ University of Ljubljana, Faculty of Natural Sciences and Engineering, Department of Textiles, \\ Graphic Arts and Design, Chair of Information and Graphic Arts Technology, Ljubljana, Slovenia \\ ${ }^{2}$ Plečnik House, Ljubljana, Slovenia
}

\begin{abstract}
In this research the development of the framework for 3D interpretation of Plečnik's Žižka Monument is presented. Jože Plečnik was a very known Slovenian architect, that design many personal, public and sacral buildings, mainly in Ljubljana, Wien and Prague. The design of Jan Žižka (Czech commander-in-chief) monument was never realised and was therefore a subject of the research of Plečnik's specialists. The features of the monument can be, according to their shape, topology and level of details, basically divided in two parts, i.e. 1. architectural part that is chalice-like stage and 2. eight human and one animal (horse) models that are more organic and highly detailed. The experimental part presents a framework for the inventory of available documentation that were collected and categorised, processed and selected with the purpose of further procedures. After the examination and the analysis of the documentation, the next step of determination and extraction of graphic, artistic and stylistic information from the documents were performed and implemented in 3D models of architectural and sculptural part. The research included also preparation of the models, 3D printing, assembly and finishing. The last phases of the framework were defined as exhibition, promotion and evaluation. In the results the overall framework for the creation and construction of $3 D$ interpretation is presented and estimated.
\end{abstract}

Key words: Žižka monument, architect Jože Plečnik, cultural heritage, 3D reproduction, framework determination

\section{INTRODUCTION}

Implementation of workflows including digital data and media in documentation, preservation and presentation of cultural heritage is a multi-layered process. After the acquisition of the target data, the processes of data storage, archivation and managing are interlaced with the aim of keeping the data accuracy and adding them values with the processing and analysis. In the steps that follow, i.e. presentation, interpretation and reproduction, 3D technologies (3D scanning, 3D printing, 3D computer aided modelling and design) are widely used and applicable due to their accuracy, repeatability and mostly non-invasive nature. The implementation of these technologies in the framework, however, should not be overlooked especially to the more subtle aspects of the cultural object(s) included in the study, i.e. preserving the details of the work and author's style.

3D printing is strongly established in cultural heritage for preservation, restoration and reproduction of cultural assets (Balletti et al, 2017). 3D printed objects can be in cultural heritage used for study and research, as an accessible media for blind and visually impaired persons in museums and galleries, for restoration and reproductions, for 3D interpretations as didactic tools etc. Authors Saorin et al (2017) presented 3D interpretation of sculptural heritage as an educative tool. In the research, 2D digital and tangible 3D printed replicas were produced and tested as spatial interpretation features on the users (students). The results shown that 3D approach (3D models, 3D prints, 3D interactive presentations) was more successful in teaching and learning process in comparison with classical 2D approach (Saorin et al, 2017).

Many researchers discovered that 3D prints are risk-free accurate reproductions of a cultural and natural heritage artefacts which physical properties are important. Authors Wilson et al (2018) demonstrated that when considering semantic differentials, exploratory factor analysis and statistic physical properties of 3D printed replicas can be evaluated by the visitors of the museums. In the research, six different 3D prints were analysed produced with different 3D printing technologies. Methodology inductive creation of the categories was used to define categories of the replicas surface texture, weight and aesthetic value. The results found out that the most important was verisimilitude, robustness, quality (Wilson et al, 2018). 
Rossetti et al. used rapid prototyping and 3D printing to construct accessible interactive 3D architectural objects of cultural sites. 3D models, 3D printed tactile reproduction and interactive solutions that enabled to the blind persons the audible explanation of the semantic information were tested. The results presented that the approach was a suitable accessible extension of the exhibited objects that offer to the blind person's autonomy and satisfying exploration of the cultural heritage (Rossetti et al, 2018).

The aim of the research is the establishment of a framework and the presentation of the initial phases of 3D reproduction of Žižka monument, i.e. a non-realised work of a known Slovenian architect Jože Plečnik. The main challenge of the research was the documentation, which was inconsistent in terms of included elements (architectural part, number of figures) and figures details (role of the figures, requisites), and consequently the definition of the robust framework that would result in successful 3D interpretation.

\section{EXPERIMENTAL}

The proposal for the 3D reproduction of Žižka monument was launched by the Plečnik House in Ljubljana. Jan Žižka was a famous Czech army leader and the monument was meant to be settled in Prague. The monument was never realised, presumably due to some nationalistic standpoints of the Chech committee in Žižka monument competition (year 1913) (Berglund, 2017).

At the beginning of experimental only the starting and final framework phases were known, i.e. documentation and final exhibition of the 3D reproduction in Plečnik house (title of the Exhibition: Plečnik and the Sacred). During the development-creative process, the following phases were defined: 1 . analysis of documentation, 2. interpretation with 3D modelling, 3. 3D printing, 4. assembling and finishing, 5. exhibition and promotion and 6. evaluation, as is presented in Figure1.

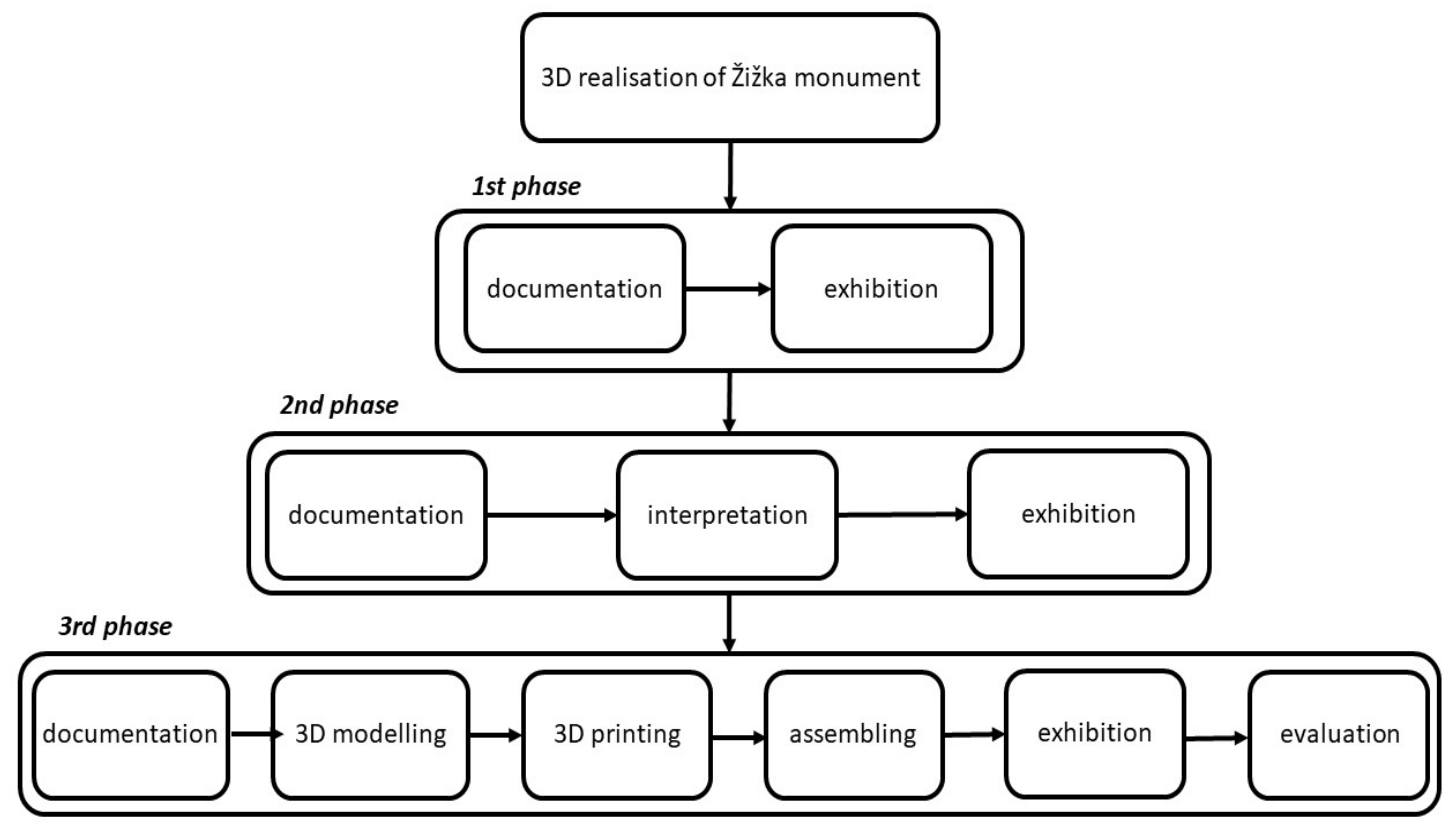

Figure 1: Framework of 3D interpretation of Plečnik's Žižka monument

\section{RESULTS AND DISCUSSION}

In the results the framework is presented with the determined sequence of the research phases and the steps for the creation of the 3D reproduction. Besides, initial 3D prototypes and 3D models of the geometrical stage of the monument and complex humans' and animal models are shown. 


\subsection{Documentation and analysis}

\section{Documentation}

Plečnik drew many sketches and architectural plans for the monument and presumably the last versions were also the inspiration for the construction of a wooden scale model, which documentation is actually limited to only one photo with a side image acquisition and non-detailed features image presentations. Besides a photo of a wooden scale model, the accessible documents (provided by Plečnik house and The Museum and Galleries of Ljubljana) of monument were: two hand drawn sketches of the author, one architecture plan and one two pages long written source (Berglund, 2017). The provided documents were not consistent, revealing different possibilities of performance and especially including almost no information about the details of monument elements (figures and requisites). Consequently, the research work included gathering and analysis of additional historical (written and image) references about Husite movement, Husite soldiers, Czech national hero Jan Žižka and battle and prayer equipment (caliche, sword, shield) and Plečnik expression style (when presenting national leaders, horses and and battle and prayer requisites).

\section{Processing and analysis of the documents}

According to the professional opinion of the specialists in Plečnik creations the photo of wooden scale model of the monument could have been taken as the most relevant reference for further work, however in the photo there were only silhouettes of the elements reproduced. With the image processing the parts of the photo were processed with the aim to reveal additional details of the elements as is presented in Figure 2.
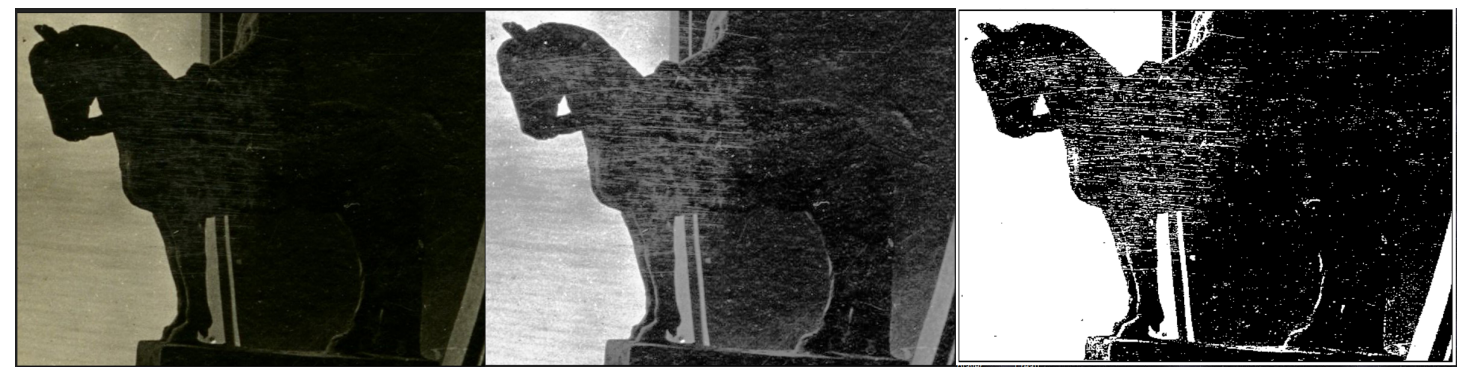

Figure 2: Part of the photo "Plečnik house" (Berglund, 2017) of a wooden model and two processed images

The results of image processing discovered that the methodology was not successful enough, so that the further analysis was based mainly on observational studies of the photo of wooden scale model and with the cues of spatial perception deduction of the possible topology of the parts of the monuments.

Framework of documentation phase is presented in Figure 3.

\subsection{D modelling}

Before 3D modelling started the parts of the monument were divided in two main parts considering the geometry, shapes and forms in the illustrated and photo references, i.e. architectural part and sculptural part. Architectural part consisted of monument foundation: a.) three level structure - base with stairs and plato level carrying the pillars and the altar carrying main caliche and cavalry Jan Žižka), b.) caliche in a form of one quarter of hemisphere and c.) five pillars. The sculptural part included: a.) one monk and one husite soldier standing on the plato level; b.) military commander Jan Žižka on the horse standing on the altar and five Husite soldiers each standing on pillars. The sculptural part was further analysed and in 3D modelling phase considered as figures (monks, commander and Husite soldiers), clothes, shoes and accessories (coats, trousers, caps, etc.) and requisites (caliche, swords, shields, helmets).

The 3D modelling phase consisted of two experimental parts. The first part was the analysis of possible automatized approaches for extracting 3D models from hand drawn illustrations and one photo of wooden scale model (Berglund, 2017; Chen et al, 2013; Jackson et al, 2017). The second part was the manual detailed modelling which special attention was on figure/cloths/requisite details and geometry of the architectural part. In Figure 4 framework of the 3D modelling phase is shown. 


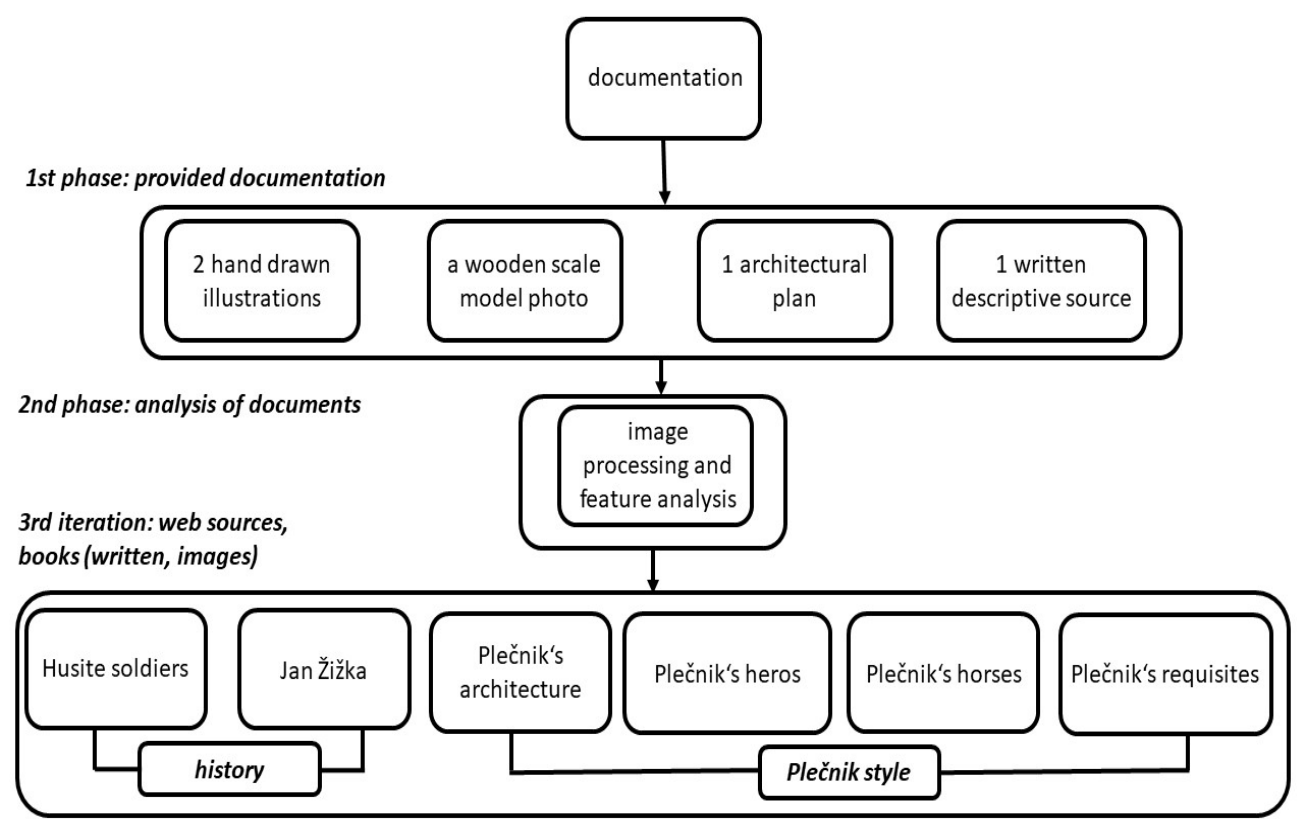

Figure 3: Framework of documentation phase and analysis

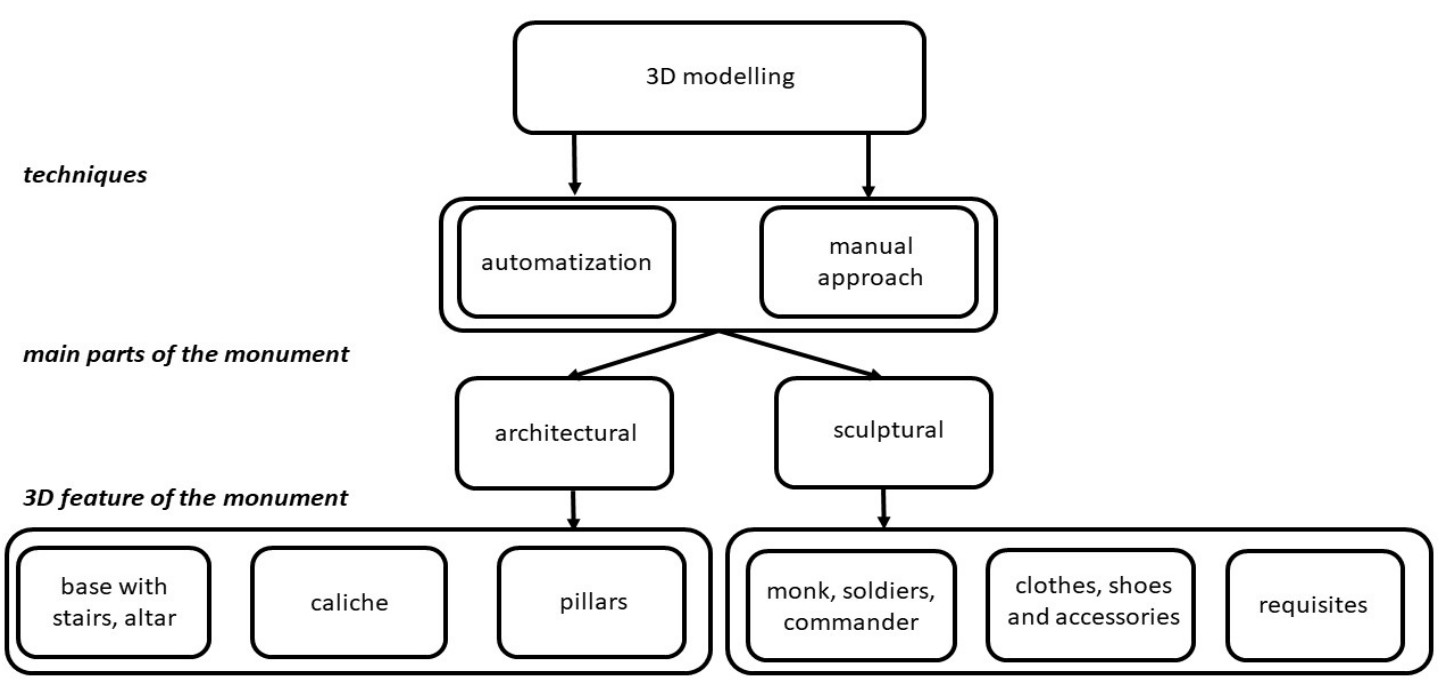

Figure 4: Framework of the 3D modelling

The first part of figures creation was performed using a programme Make Human, an open source tool for character modelling. The characters were then transferred to 3D program Blender where dresses were added and other characters' accessories, such as swords, shields, a chalice and helmets. When modelling the figures, sculpt tools were used to add details and their correct features. For creation of clothes, the process of cloth simulation was used and sculpt tools for correction of details. On figure 5, a 3D model of a soldier is shown.

The architectural part of the monument was also modelled using Blender. The most challenging part to create was a cut-off sphere/chalice and changing thickness of its wall. The sphere is the largest part of the monument and bearing in mind the FDM printing technology it was necessary to create a model with a suitable well modelled topology. 


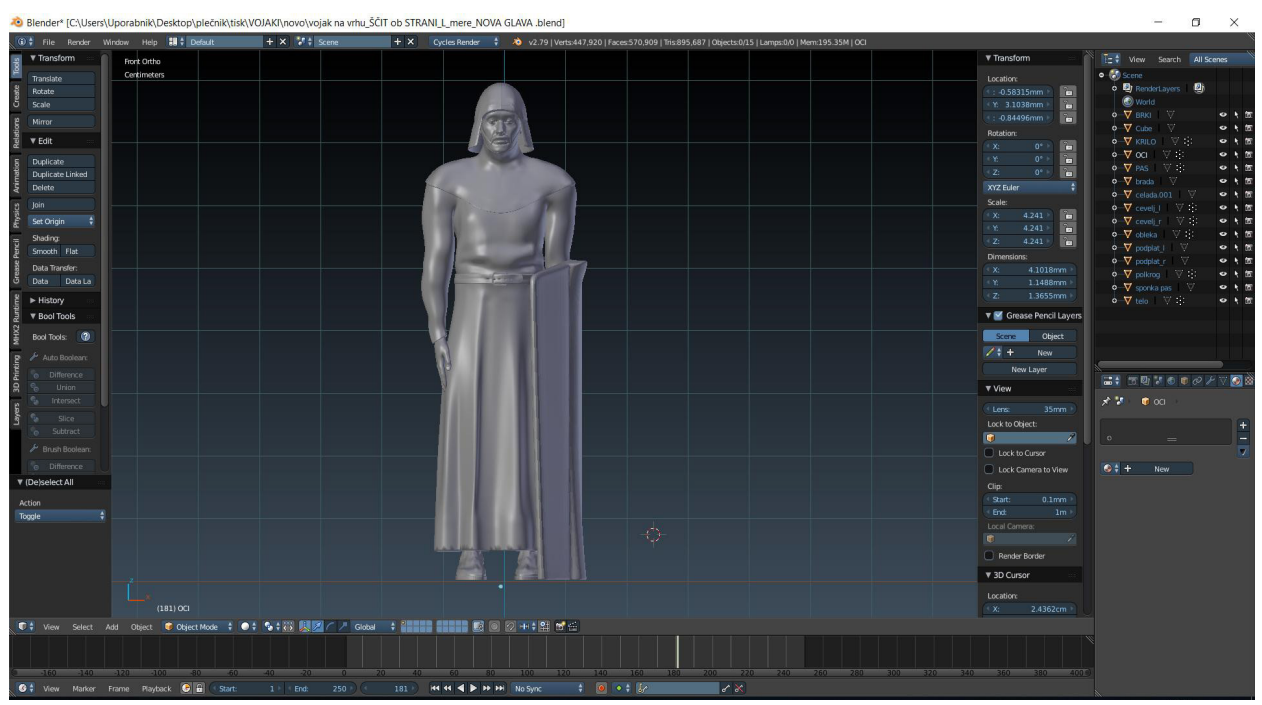

Figure 5: 3D model of a soldier in Blender computer programme

\subsection{D printing}

Before the 3D printing, the models were prepared according to the topology properties (level of details) of the parts of the monument's 3D model. The framework of 3D printing and preparation of the models is presented in figure 6.

3D model of the architectural part was divided (cut) into smaller elements according to the demands of the used 3D printer. When cutting the model, it was necessary to create smaller object with planes that can be easily put and glued together. It is also important to print the model that doesn't require much support structure for printing. Our monument was divided into 58 smaller parts. 3D printing process was performed with two technologies, i.e. stereolithography (figures with clothes, accessories and requisites) and FDM (architectural parts).

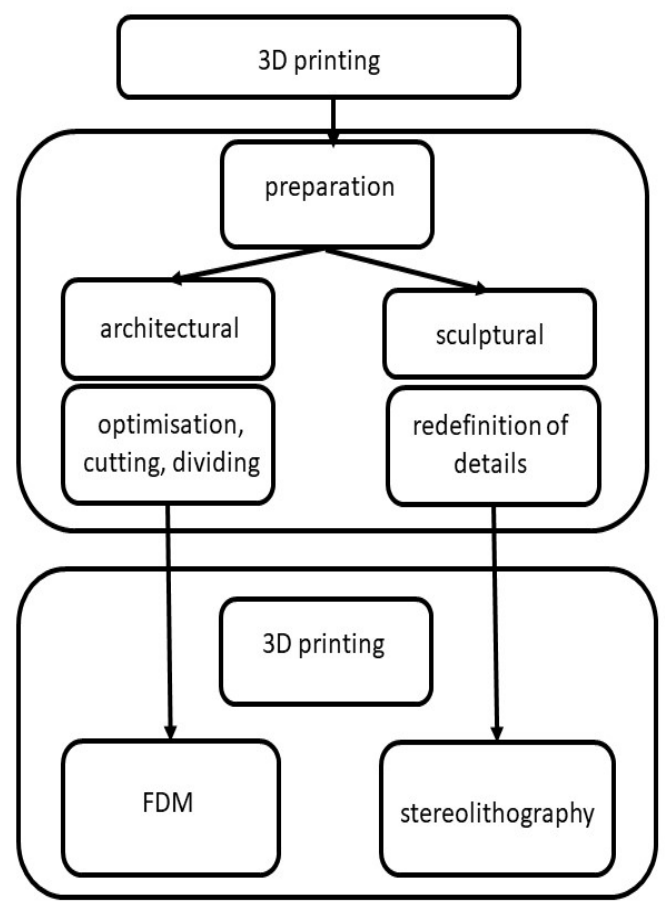

Figure 6: Framework of 3D printing and preparation of the models 


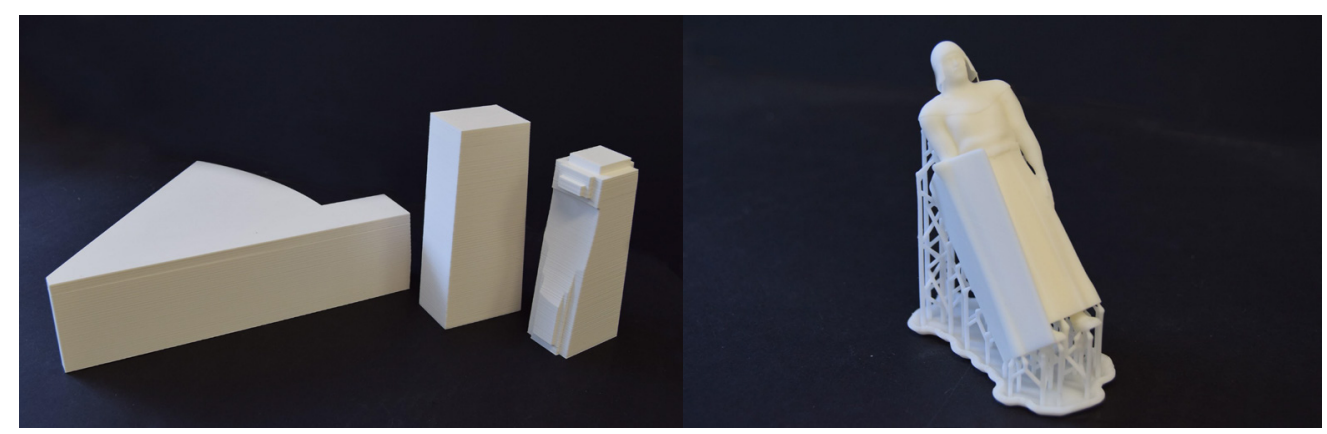

Figure 7: Parts of the monument printed with FDM 3D printing technology on the left and a model of a soldier printed with stereolitography on the right

\subsection{Assembling and finishing}

Assembling and finishing of the 3D printed reproduction included gluing of the architectural parts, sanding with sanding paper, UV fixation of 3D objects printed with stereolithography, removing of the support structure, filling seams of the model with putty and colouring with matte white colour spray. Figure of framework of assembling and finishing of 3D printed objects is presented in Figure 8.

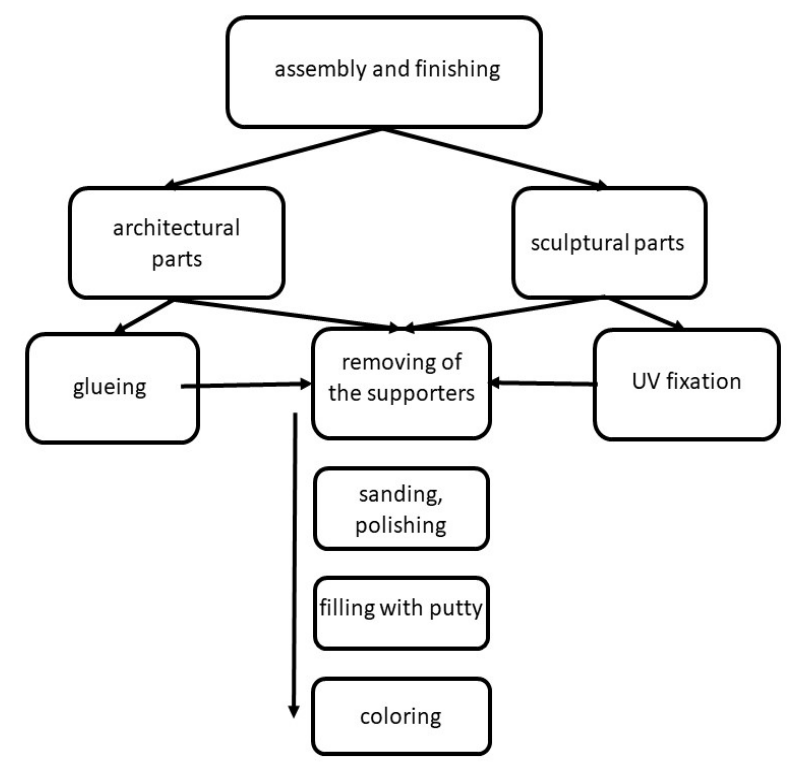

Figure 8: Framework of assembling and finishing of 3D printed objects

On figure 9, process of removing supporters from a model printed with stereolitography is presented and the phase of gluing architectural parts of the model printed with FDM technology.

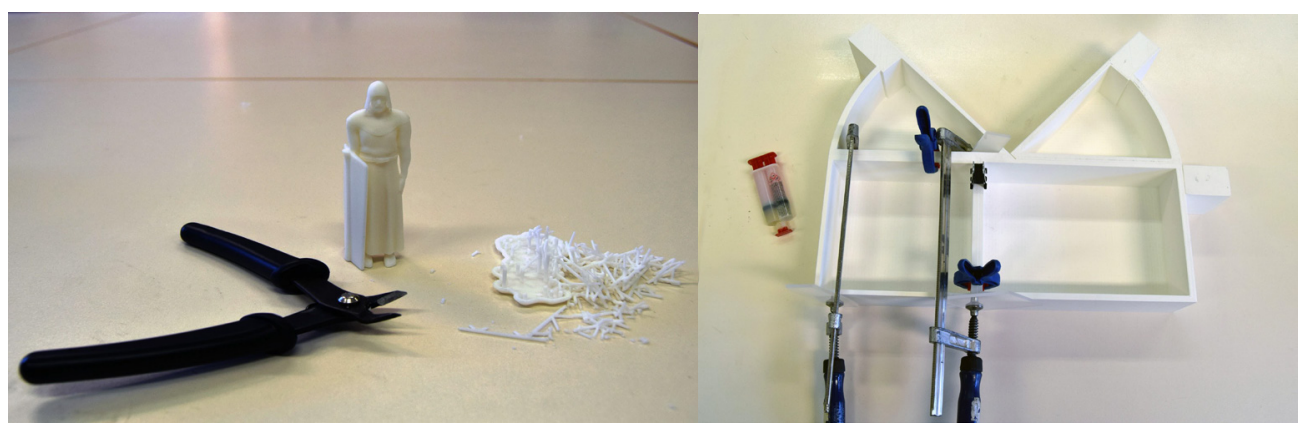

Figure 9: Two phases of 3D printed model assembling, removing of supporters and glueing 


\subsection{Exhibition and promotion}

The model of the Žižka monument is going to be presented in The Plečnik house in Ljubljana. Due to its fragility, especially models of human figures and a horse have some small, fragile parts, is going to be protected with the transparent cover. Visitors of the museum will be able to explore and evaluate the scale model of Plečnik's unrealised project.

\subsection{Evaluation}

In further researches, the evaluation of the results is going to be performed in more phases. Printed 3D interpretation is going to be analysed considering geometrical accuracy and reproduction of the style and details in architectural and sculptural parts. Moreover, the focus of the analysis is going to be also the observers' estimation, when comparing references, visualisation and 3D printed reproduction.

\section{CONCLUSIONS}

In the contribution the development of framework for Žižka monument 3D reproduction is presented. Due to non detailed illustration and image references 3D reproduction was not possible to be performed with a noticeable level of interpretation that was implemented especially in 3D modelling phase. With the use of 3D technologies it was possible to "make alive" Žižka monument that otherwise would remain documented only in the few references. The 3D printed monument is going to be a permanent item exhibited in Plečnik house in Slovenian capital town Ljubljana.

\section{REFERENCES}

[1] Balletti, C., Ballarin, M., Guerra, F.: "3D printing: State of the art and future perspectives", Journal of Cultural Heritage, 26, 172-182, 2017. doi: 10.1016/j.culher.2017.02.010

[2] Berglund, B.: "Castle and Cathedral in Modern Prague: Longing for the Sacred in a Skeptical Age", (Central European University Press, London, 2017), page 280.

[3] Chen, T., Zhu, Z., Shamir, A., Hu, S.M., Cohen-Or, D.: "3-Sweep: Extracting Editable Objects from a Single Photo", ACM Transactions on Graphic, 32 (6), 195, 2013.

[4] Jackson, S.A., Bulat, A., Argyriou, V., Tzimiropoulos, G.: "Large Pose 3D Face Reconstruction from a Single Image via Direct Volumetric CNN Regression", IEEE International Conference on Computer Vision (ICCV, Venice, Italy, 2017), pages 1031-1039.

[5] Rossetti, V., Furfari, F., Leporini, B., Pelagatti, S., Quartaa, A.: “Enabling Access to Cultural Heritage for the visually impaired: an Interactive 3D model of a Cultural Site", Procedia Computer Science, 130, 383-391, 2018. doi: 10.1016/j.procs.2018.04.057

[6] Saorín, J.L., Carbonell-Carrera, C., Cantero de la Torre, J., Meier, C., Aleman, D.D.: “ThreeDimensional Interpretation of Sculptural Heritage with Digital and Tangible 3D Printed Replicas", Turkish Online Journal of Educational Technology 16 (4), 161-169, 2017.

[7] Wilson, P.F., Stott, J., Warnett, J. M., Attridge, A., Smith, M. P., Williams, M. A.: "Museum visitor preference for the physical properties of 3D printed replicas", Journal of Cultural Heritage, 32, 176-185, 2018. doi: 10.1016/j.culher.2018.02.002

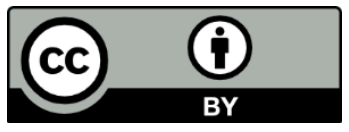

(C) 2018 Authors. Published by the University of Novi Sad, Faculty of Technical Sciences, Department of Graphic Engineering and Design. This article is an open access article distributed under the terms and conditions of the Creative Commons Attribution license 3.0 Serbia

(http://creativecommons.org/licenses/by/3.0/rs/). 